\title{
O ethos capitalista weberiano e a afetividade no comércio mineiro*
}

\author{
The weberian capitalist ethos and affectivity on commerce in Minas Gerais
}

\author{
Amon Narciso de Barros ${ }^{1}$ \\ Wescley Silva Xavier ${ }^{2}$ \\ Rafaela Costa Cruz ${ }^{3}$ \\ Alexandre de Pádua Carrieri ${ }^{4}$ \\ Gusttavo Cesar Oliveira Lima ${ }^{5}$
}

\begin{abstract}
Resumo
Este texto é fruto de uma pesquisa realizada ao longo de dois anos, que problematizou a forma como as pessoas exerciam o comércio em Minas Gerais em meados do século passado. As atividades que o comerciante desempenhava em seu trabalho, àquele tempo, eram parte constituinte de sua identidade social. Com base nisso, questionou-se o ethos capitalista weberiano no contexto do comércio mineiro de meados do século XX. Os argumentos foram construídos, em grande parte, confrontando ideias de Max Weber aos dados obtidos na pesquisa empírica. Foram realizadas 33 entrevistas semiestruturadas com pessoas entre 60 e 95 anos que atuaram no comércio volante. Os relatos foram abordados por meio da Análise de Conteúdo, com base no levantamento das temáticas identificadas ao longo dos discursos (BARDIN, 2004). Nas entrevistas, foram identificados elementos marcadamente característicos do capitalismo protestante e traços de personalismo e de "irracionalidade" herdados dos lusitanos (HOLANDA, 1995). Aparentemente, os sujeitos pesquisados valiam-se do afeto nas suas relações comerciais não apenas porque desejavam ter um cliente a mais - apesar de ser esse um fator a ser considerado -, mas porque viam sua vida e seu trabalho como circunstâncias entremeadas. Dessa forma, verifica-se neste artigo que os comerciantes estudados caracterizam-se como um tipo híbrido entre o que Weber denominou tradicional e moderno, em que aspectos afetivos, morais e racionais se entrecruzam.
\end{abstract}

Palavras-chave: Trabalho. Comércio. Comerciante brasileiro.

\footnotetext{
* Os autores agradecem ao CNPq pelo financiamento da pesquisa. Agradecem também à FAPEMIG, CAPES e CNPq pelas bolsas de estudos concedidas.

${ }^{1}$ Doutorando em Administração pelo Centro de Pós-Graduação e Pesquisas em Administração (CEPEAD/UFMG); Mestre em Administração (CEPEAD/UFMG). Endereço: CEPEAD/FACE/UFMG - Av. Antônio Carlos, 6627 - Sala 4012, Pampulha, CEP 32170901, Belo Horizonte - MG, Brasil. E-mail: amonbarros@gmail.com

2 Doutorando em Administração pelo Centro de Pós-Graduação e Pesquisas em Administração (CEPEAD/UFMG); Mestre em Administração (CEPEAD/UFMG). Endereço: CEPEAD/FACE/UFMG - Av. Antônio Carlos, 6627 -Sala 4012, Pampulha, CEP $32170-$ 901, Belo Horizonte - MG, Brasil. E-mail: wescleysxavier@yahoo.com.br

${ }^{3}$ Mestre em Administração pelo Centro de Pós-Graduação e Pesquisas em Administração (CEPEAD/UFMG); Professora da Faculdade de Gestão de Negócios/UFU. Endereço: Av. João Naves de Ávila, 2121 - Bloco 1F/sala 1F 238, Santa Mônica, CEP 38408-100, Uberlândia - MG, Brasil. E-mail: correiodarafaela@yahoo.com.br

${ }^{4}$ Doutor em Administração pelo Centro de Pós-Graduação e Pesquisas em Administração (CEPEAD/UFMG); Professor Associado do CAD/UFMG. Endereço: CEPEAD/UFMG - Av. Antônio Carlos, 6627, Sala 4012, Pampulha, CEP 32170-901, Belo Horizonte - MG, Brasil. E-mail: alexandre@face.ufmg

5

Mestre em Administração pelo Centro de Pós-Graduação e Pesquisas em Administração (CEPEAD/UFMG); Professor da Fundação Comunitária de Ensino Superior de Itabira. Endereço: Rua Venâncio Augusto Gomes, Prédio 3, sala 202, Major Lage de Cima, CEP 35900-842, Itabira - MG, Brasil. E-mail: gusttavocesarlima@bol.com.br
} 


\begin{abstract}
This text is the result of a research carried out over two years, which focused on the way how people practiced trade in Minas Gerais, Brazil, in the middle of the last century. At that time, the activities performed by the merchant were part of his social identity. Based on this assumption, the Weberian capitalist ethos is questioned in the context of commerce in Minas Gerais in the middle of the 20th century. The arguments were mostly constructed comparing Max Weber's ideas to data obtained in the empirical research. Thirty three semi-structured interviews were performed with people between 60 and 95 years of age who worked as mobile merchants. The reports were approached through Content Analysis, based on the survey of themes identified during the speeches (BARDIN, 2004). In the interviews, markedly characteristic elements of the protestant capitalism and traits of personalism and "irrationality" inherited from the Portuguese people (HOLANDA, 1995) were identified. Apparently, the subjects under study drew on ties of affection in their trade relations not only because they wanted one more client - although it is a factor to be taken into account - , but because they saw their life and labor as interconnected circumstances. Therefore, one verifies in this paper that the merchants under study are characterized as a hybrid type between what Weber named traditional and modern, where affective, moral, and rational aspects weave into each other.
\end{abstract}

Keywords: Labor. Commerce. Brazilian merchant.

\title{
Considerações Iniciais
}

A lógica empresarial busca minimizar o espaço para relações que fujam do formal e que se sustentem sobre valores baseados em confiança pessoal e afeto, embora o ambiente em que se efetiva envolva, em grande medida, essas questões. Vendedor e comprador são, em geral, socializados, educados e treinados no ambiente de trabalho para que se coloquem frente a frente e analisem fria e racionalmente o valor que se pede por uma mercadoria e o quanto ela vale. Em pesquisa realizada entre 2007 e 2009 com sujeitos que praticavam o comércio em Minas Gerais em meados do século passado (como mascates, caixeiros-viajantes ou tropeiros), verificou-se que suas práticas comerciais estabeleciam relações que não se restringiam a permutas simplesmente comerciais ou econômicas. Havia, explicitamente, trocas pautadas por valores éticos.

Este texto é, portanto, fruto de uma reflexão sobre um trabalho de pesquisa realizado ao longo de dois anos, no qual se problematizou a forma como as pessoas exerciam o comércio em Minas Gerais em meados do século passado, e se buscou trazer à tona elementos que pudessem servir para a análise das práticas comerciais de hoje. Ao longo da pesquisa perceberam-se algumas interseções entre a relação desses sujeitos com seus negócios e o ethos capitalista, trabalhado por Max Weber.

Havia, no ato de comércio, ao que tudo indica, uma implicação direta do "sujeito que vendia". Ele efetivamente tinha as atividades desempenhadas em seu trabalho como parte constituinte de sua identidade social. Os padrões éticos utilizados para julgar as atitudes tomadas eram os mesmos tanto no "mundo da vida" (relacionamentos pessoais e vivências do cotidiano familiar) quanto no mundo dos negócios (contexto da empresa ou de seu empreendimento próprio). Havia também uma implicação moral do sujeito, no ato de negociar, que não se restringia apenas ao momento da troca. Na época, apesar de a sociedade ser menos integrada do ponto de vista da tecnologia de comunicação, podiam ser identificadas representações compartilhadas sobre o "bem comportar-se e o bem tratar", o "ser honesto" e a "honra", que, ao que parece, eram dotadas de uma significação mais específica, implicando o sujeito por inteiro. As representações verbalizadas atestam que os negócios deviam ser feitos baseados em confiança e honestidade e que as relações comerciais deviam ser entremeadas de amizade, cordialidade e boa educação. 
Percebe-se que a busca pela regulamentação dos comportamentos é um movimento infindo no sentido de padronizar as relações produtivas e comerciais. Parece haver um reforço para que exista uma dissociação entre as atividades produtivas e a vida privada dos sujeitos, separação que não foi percebida nos relatos dos entrevistados. Vilela (1999, p. 39) aponta "os preceitos da racionalização crescente da vida, enquanto a ideologia que rege o comportamento social espalha-se pelo mundo afora sem respeitar fronteiras", levando a que até as mais diferentes culturas sejam transformadas pelo modelo do capitalismo ocidental.

O mascate, o tropeiro e o caixeiro-viajante - sujeitos da pesquisa que serviu de ponto de partida para a presente discussão - veem a atividade profissional como parte constitutiva da vida pessoal e social das pessoas. Apesar de, geralmente, conseguirem "fazer dinheiro" com sua atividade e conquistar certa ascensão social, pautavam seus comportamentos por uma lógica na qual trabalho remunerado e lucro serviam de meios para a conquista de uma vida melhor para a família e, num sentido menos romântico, para a acumulação financeira não ostentadora, que se justificava pela constante perspectiva de uma possível necessidade futura.

Visando discutir essas questões a respeito da separação dos valores entre o "mundo do trabalho" e o "mundo da vida" e das orientações dadas ao negócio que se distancia da empresa capitalista racional, apontam-se, neste texto, argumentos que problematizam o ethos capitalista no contexto do comércio em meados do século passado. Tal exame foi construído com base em referências bibliográficas que discutem o capitalismo e no confronto destas com os dados obtidos em pesquisa empírica. A pesquisa resgatou práticas de tropeiros, mascates e caixeiros-viajantes de Minas Gerais, tentando observar a ressonância de heranças históricas dessas práticas para o comércio e para sua lógica atual. Observe-se que o risco de "presentificação" dessas práticas é permanente, além do fato de estas terem sido analisadas por meio de olhares contemporâneos.

O artigo faz essa confrontação em três seções de discussão teórica. Antes delas, aponta-se o suporte metodológico utilizado na pesquisa sobre a prática do comércio. A segunda trata do contraste entre o capitalista protestante modelo e os comerciantes entrevistados, cujas relações de troca estavam margeadas por afetividade. A terceira seção, em contraponto às características do modelo weberiano discutido, inclui no debate os elementos culturais brasileiros, sobretudo os traços de personalismo do relacionamento interpessoal. A quarta seção apresenta uma discussão acerca da relação entre o afeto e as relações comerciais. Seguem então as considerações finais, em que foi importante destacar eixos de discussão correlatos e agenda de pesquisa complementar.

\section{Caminho percorrido}

De acordo com González Rey (2005), a realidade social é bastante intricada e não se consegue acessá-la totalmente em toda sua complexidade usando métodos quantitativos. Assim, para esse autor, adotar um caminho qualitativo é propor-se a buscar algum entendimento dessa realidade complexa. Desse modo, nesta pesquisa optou-se por percorrer tal caminho qualitativo. A pesquisa qualitativa tem um caráter construtivo interpretativo do conhecimento e implica "compreender o conhecimento como produção e não como apropriação linear de uma realidade que se nos apresenta" (GONZÁLEZ REY, 2005, p. 5).

Para a consecução deste caminho qualitativo foram entrevistadas trinta e três pessoas que tinham entre 60 e 95 anos e atuaram como praticantes do comércio volante, isto é, aquele em que o vendedor se desloca para fazer as vendas. Especialmente, foram interrogados mascates, tropeiros e caixeiros-viajantes. As entrevistas eram semiestruturadas e as análises concentradas em aspectos da trajetória profissional e da história de vida desses sujeitos, contada por eles mesmos. Também foram interrogados dois representantes comerciais atuais para verificar as relações possíveis entre as práticas "antigas" e "contemporâneas", confrontando-as. É 
interessante destacar que, nas diversas entrevistas coletadas, os sujeitos de pesquisa se movimentavam para evidenciar suas próprias experiências em um processo onde buscavam contextualizar suas práticas e seu cotidiano aos entrevistadores. Ao narrar, os sujeitos construíam tramas sobre os fatos vividos, guardados em suas memórias, situando seu mundo na dinâmica social-histórica.

Os relatos foram tomadas nas cidades em que os sujeitos moram hoje em dia. Especificamente, os dados foram coletados em quatro cidades mineiras, representando mesorregiões de Minas Gerais, a saber: Araguari (representando o Triângulo Mineiro); Montes Claros (Norte de Minas); Juiz de Fora (Zona da Mata); e Lavras (Sul de Minas). Na maior parte dos casos, os relatos foram colhidos na residência do entrevistado. O registro foi ainda complementado por notas de diário de campo e fotos de objetos de uso pessoal. Os trechos de falas que ilustram esse trabalho foram selecionados por serem representativos do conjunto de ideias que se queria apresentar. As transcrições são fieis às falas dos entrevistados, embora algumas correções gramaticais tenham sido feitas para ampliar a fluidez do texto.

As narrativas coletadas permitiram compreender melhor a realidade vivida pelo grupo de entrevistados, e isto contribuiu para que se encaminhasse para a "[...] construção de um objeto científico, cujo fundamento é um conjunto real e histórico de relações sociológicas e empíricas vividas por um grupo" (MARRE, 1991, p. 110). Durante a coleta de dados, recorreu-se à ideia de "mosaico", baseada em Goldenberg (1997) e Marre (1991), no sentido de que cada narrativa era uma peça do quebra-cabeça que, ao ser analisada, adicionava um melhor entendimento à possível compreensão do todo. Conjuntamente com as entrevistas coletadas (gravadas), era elaborado pelos entrevistadores um diário de campo. Os registros no diário de campo foram importantes para uma melhor análise das entrevistas realizadas. O diário de campo, ou notas de campo, como as denomina Agar (1980), são considerados fontes importantes para o registro das conversas, interpretações, e sugestões para informações adicionais a serem buscadas e elucidadas no retorno do campo das pesquisas.

Os dados levantados foram analisados por meio da análise de conteúdo, com base no levantamento das temáticas identificadas ao longo dos discursos (BARDIN, 2004). Esta técnica visa denotar de maneira plausível elementos ocultos da linguagem humana, além de organizar e possibilitar a descoberta de significados originais dos seus elementos manifestos (BARDIN, 2004; TRIVIÑOS, 1987). A técnica adotada visou abranger o repertório interpretativo dos sujeitos e os elos lógicos entre as categorias. A análise, com a apreciação dos textos resultantes da transcrição das entrevistas e do diário de campo, concluiu a elaboração de inferências em séries de significações (BARDIN, 2004). Por meio dos conteúdos manifestos e latentes, foi oportuno vivificar os sentidos relacionados ao comércio volante, explorando suas origens, além de trabalhar relações e consequências.

Uma vez que os indivíduos não relatam sua experiência em ordem cronológica, e por admitir que o discurso não se constitui sozinho, mas na interação com outros discursos e com a realidade em si, foram realizadas leituras descontínuas das narrativas e agrupamento dos recortes temáticos. Essas leituras focaram-se na apreensão da "visão de mundo" defendida e organizada pelos entrevistados, implícita ou explicitamente, por meio de padrões e recorrências que surgiram em torno de temas específicos. Os principais temas que apareceram foram as relações comerciais produzidas por estes sujeitos, as relações de afetividade contruídas, e a imbricada relação entre o afeto e o comércio. Temas que serão trabalhados a seguir.

\section{O Capitalista Protestante Weberiano e os Comerciantes Volantes}

Como aponta Vilela (1999, p. 4), para Max Weber o capitalismo moderno se caracteriza "pela racionalidade no tratamento dos fatores de produção, o que o distingue do capitalismo tradicional baseado na ganância, na especulação e no oportunismo". Weber (1987, p. 33) menciona que no capitalismo moderno o bem máximo da nova ética 
[...] é a obtenção de mais e mais dinheiro, combinada com o estrito afastamento de todo gozo espontâneo da vida é, acima de tudo, completamente destituída de qualquer caráter eudemonista ou mesmo hedonista, pois é pensado tão puramente como uma finalidade em si [...]. O homem é dominado pela geração de dinheiro, pela produção de dinheiro, pela aquisição encarada como finalidade última da sua vida. A aquisição econômica não mais está subordinada ao homem como um meio de satisfazer suas necessidades materiais. Esta inversão daquilo do que poderíamos chamar de relação natural, tão irracional de um ponto de vista ingênuo, é evidentemente um princípio orientador do capitalismo [...].

As conceituações weberianas valem para respaldar o que se encontrou no plano empírico e auxiliam na compreensão das ideias que se pretende desenvolver. Os sujeitos que foram entrevistados eram todos comerciantes e exerciam, principalmente, atividades econômicas. Para Weber (2004, p. 37), a ação é "[...] economicamente orientada [quando está] referida a cuidados de satisfazer o desejo de obter certas utilidades". Nesse sentido, as trocas partem do "[...] compromisso de interesses entre os participantes, pelo qual se entregam bens ou possibilidades como retribuição recíproca" (WEBER, 2004, p. 43). Trocas estas feitas de modo racional, ou seja, sempre economicamente orientadas, ainda que na relação estabelecida exista qualquer traço de afetividade. É o que se pode notar no relato do entrevistado José Pinto, que atesta só conceder prazo de pagamento às pessoas que conhece e confia:

Não era muito chegado em dar prazo não. Só depois que eu conhecia... Se eu ver que você queria levar algo e o dinheiro não dava, eu dizia "pode levar uma coisa", aquele coisa bem pontual. A gente tem que conhecer o sujeito primeiro. Até hoje no comércio eu não gosto de dar prazo. Outro dia eu vendi uma boiada e sujeito chegou e ofereceu cinquenta e cinco. Eu disse: "não, te vendo a cinquenta 'conto' a arroba, tiro cinco conto da venda realizada [se o pagamento for à vista]. (Comunicação oral).

Por meio deste fragmento, pode-se notar que as relações comerciais que se estabeleciam eram, como esperado, pautadas pela expectativa do lucro. Mas, ao mesmo tempo, pode-se perceber um elemento de afetividade presente na ideia de que o critério que se deve respeitar para fornecer prazo é "conhecer o cliente". Contudo não se pode esquecer que tal comportamento não exime o anseio por lucros que incorram em menores riscos.

As relações comerciais estabelecidas e a trajetória de vida desses comerciantes exibiam, entretanto, certa ambiguidade. Se, por um lado, eles percorriam a trajetória do capitalista protestante modelo, visando à acumulação de capital e às trocas racionais; por outro, tinham suas relações de troca margeadas por afetividade. Sua atuação profissional tinha elementos de ação tradicional (de acordo com tradições, usos e costumes), ação afetiva (orientada por emoções e sentimentos) e de ações racionais em relação a fins (causal ou logicamente compatível com os fins propostos) (WEBER, 2004).

Weber (1987, p. 5-6) observa que

[n]a medida em que as operações são racionais, toda ação individual das partes é baseada em cálculo. A inexistência de um cálculo realmente apurado, o fato de o procedimento ser pura adivinhação, ou simples tradição e convenção, ocorre ainda hoje em toda forma de empresa capitalista em que as circunstâncias não exijam precisão absoluta. Esses fatos, entretanto, pouco afetam a racionalidade da aquisição capitalista. 
Nos termos do próprio Weber (2004, p. 42), pode-se considerar que a ação dos comerciantes entrevistados tinha os seguintes elementos que possibilitam a sua classificação como "gestão econômica racional":

- distribuição planejada das utilidades ${ }^{6}$ entre o presente e o futuro, para controlar a disponibilidade destas;

- distribuição daquilo que dispunham entre aplicações variadas e classificadas de acordo com a importância;

- abastecimento planejado das utilidades tidas como necessárias;

- aquisição do poder de disposição sobre elas.

Ora, aqui não se sugere que o cálculo racional era desconsiderado por esses comerciantes, mas fica claro que não era apenas este a conduzir as ações desses sujeitos. Algo escapava do âmbito da razão calculista. Alguns deles faziam questão de frisar as relações pessoais que estabeleciam no desempenho de suas atividades. Essa perspectiva é ilustrada pela fala na qual o entrevistado Naturib relata o empréstimo de um produto para uma cliente:

O importante é isso, saber agradar. Porque, se eu não soubesse agradar o freguês, eu não fazia o comércio que eu já fiz, não. Sabia que toda venda que eu fiz eu agradei e sigo agradando até hoje. Outro dia chegou uma dona aqui e falou comigo assim: "tô precisando de uma geladeira, mas eu não posso comprar a geladeira agora, o senhor tem uma pra vender?" "Eu tenho". "Qual é o preço?" "Vou vender pra senhora por duzentos e cinquenta, mas não aconselho a senhora a comprar não". [Ela disse] "Mas, por quê? Tem pra vender ou não tem?" "Não aconselho a senhora a comprar a geladeira que eu tenho aí porque eu gastava com ela aí quarenta e cinco conto por mês, se a senhora comprar, a conta dela com a senhora vai ser mais". "Então, a senhora faz assim, a senhora leva a geladeira emprestada e fica com ela lá uns trinta, quarenta dias, dois ou três meses até poder comprar outra". Aí ela levou a geladeira, ficou lá com a geladeira três meses. Quando deu três meses, ela veio cá e falou: "Ahh seu Naturib, é difícil um homem igual o senhor. Comprei uma geladeira nova, a geladeira do senhor eu deixava ela todo dia desligada, gastava uma base de vinte e cinco conto por mês. Comprei uma geladeira novinha e minha conta não foi a doze reais". (risos). Viu, tô satisfeito. Se fosse outro, não; queria vender. A geladeira tá até ali fora, ali. Tá ali fora. Se a gente faz com os outros, Deus faz com a gente em troco. (Comunicação oral).

Todavia se poderia ainda considerar que as relações que aparentam afetividade no trato social seriam, por vezes, coloridas de utilitarismo, como Max Weber aponta a respeito de Benjamin Franklin:

A honestidade é útil, porque assegura o crédito; do mesmo modo a pontualidade, a laboriosidade, a frugalidade, e esta é a razão pela qual são virtudes. Uma dedução lógica disto seria que, por exemplo, a aparência de honestidade bastaria quando fizesse o mesmo efeito, e um guia supérfluo dessa virtude evidentemente, pareceria a Franklin, um

\footnotetext{
${ }^{6}$ Por "utilidade", Weber (2004, p. 40) entende "[...] as probabilidades (reais ou supostas) concretas e particulares de aplicabilidade presente ou futura, consideradas como tais por um ou mais agentes econômicos cuja presumível importância como meios para os fins desse agente (ou desses agentes) orienta suas atividades econômicas". As utilidades podem ser objetos ou serviços prestados por homens.
} 
desperdício improdutivo. [...] [S]egundo Franklin estas virtudes somente o são na medida em que são realmente úteis ao indivíduo, e sendo substituíveis pela mera aparência sempre são suficientes quando o mesmo objetivo tiver sido atingido. (WEBER, 1987, p. 32).

Desta perspectiva utilitarista, poder-se-ia dizer, então, que os comportamentos personalistas adotados no trato comercial refletem determinados padrões de ação que visam unicamente ao lucro. Quanto mais pessoal fosse o relacionamento, maior seria o entendimento da empresa (representada por essa pessoa) sobre preferências, motivações e comportamentos de compra manifestados pelo cliente, que têm potencial para serem traduzidos em lucros futuros. Ou seja, o trato cortês fundamentaria, assim, o relacionamento e o atendimento personificados, o que causa maior impacto no cliente e se reflete em compras, satisfação e fidelização.

Acredita-se, contudo, que não se pode, no caso específico aqui tratado, tentar transpor por completo características do comportamento ensejadas pelo capitalismo racional para os sujeitos pesquisados. Ou seja, acredita-se que não necessariamente eles alimentavam o personalismo nas relações comerciais que travavam com fins puramente econômicos. Há relatos que atestam que esse parâmetro não justificaria o termo adotado, como o dispêndio de longo tempo numa localidade com apenas um freguês que não fazia grande volume de compras. Pintado, um dos entrevistados, afirma:

E com o tempo você vai ficando conhecido, o freguês começa a acreditar em você e, com isso, eu fiz muita amizade, tenho 16 afilhados no interior [...] eu chegava, eu ia pra cozinha da casa dos freguês. Eu não ia pra casa de perto, eu ia pra cozinha dele. Dificilmente eu almoçava em restaurante, comia na casa dos fregueses, porque eles gostavam de mim, era muito bom. E assim você faz uma amizade doida, eu montei muita casa de peça no interior, muito mesmo. Cara, eu chegava de compra, eu vendia confiando nas pessoas. Graças a Deus, eu sempre me saí bem. (Comunicação oral).

Há um elemento que Weber (1987) aponta como um dos traços fundamentais do capitalista protestante: a ideia de obrigatoriedade de aumentar o próprio capital, tarefa assumida como um fim em si. Essa empreitada não era apenas um meio de conduzir a vida particular, mas uma ética peculiar. Contudo tal característica não pode ser constatada como o valor predominante no caso dos praticantes do comércio volante. Fazia parte do comportamento relatado pelos sujeitos de pesquisa a busca pela proximidade e a tendência/vocação por familiarizar-se com outras pessoas.

Além disso, os sujeitos, em geral, justificaram os primeiros movimentos com vistas à acumulação do capital principalmente pelo anseio de se fixar em algum local e não pela acumulação em si mesma. O sustento da família também aparece como fator importante e recorrente, como ilustra o relato do entrevistado Manoel:

A esposa reclamava que os filhos estavam nascendo, criando, começando a família, a ausência da gente, não é? Mas, infelizmente, era o trabalho, e para acabar de criar os meninos tinha que seguir o serviço de viagem, que era o lucro que a gente tinha. (Comunicação oral). 
A acumulação, por outro lado, não aparece como um objetivo claro nos relatos. ${ }^{7}$ É interessante a seguinte assertiva weberiana:

\begin{abstract}
Se lhes perguntarem qual o sentido de sua atividade ininterrupta, o porquê da sua constante insatisfação com o que têm, dando assim, a impressão de ser tão desprovida de sentido para qualquer concepção da vida puramente mundana, a resposta, se soubesse de alguma, talvez fosse "para o futuro dos filhos e netos". Com mais frequência, porém, e mais corretamente, uma vez que essa razão não lhes é peculiar, mas tem a mesma eficiência para o homem "tradicional", a resposta seria simplesmente que os negócios com seu trabalho contínuo tornaram-se uma parte necessária de suas vidas. (WEBER, 1987, p. 46).
\end{abstract}

Ao mesmo tempo, a noção de dever foi uma característica que apareceu reiteradas vezes nas entrevistas. O sentimento, em relação ao trabalho, é combinado com um senso de economia que se orienta para a possibilidade de altos ganhos, embasados numa atitude de autocontrole e frugalidade (WEBER, 1987). Os entrevistados, em geral, evitavam atitudes que poderiam denotar ostentação em favor do aumento de suas economias para tempos vindouros e para o benefício da família, como apontam, por exemplo, Joaquim e Fernando respectivamente:

Quem compra o que não precisa acaba vendendo aquilo que precisa. (Comunicação oral).

Que a família pra mim é em primeiro lugar. Mas o serviço também tem que estar em primeiro lugar, né? Que dali que você tira pra manter a família, dar uma boa... um bom estudo pros filhos e... você não pode pensar só no hoje, né? Tem que pensar no amanhã, no depois, no futuro deles. Então, por isso que a gente dedica com muita força aí e vai matando um leão por dia. (Comunicação oral).

Segundo Weber (1987, p. 46-47), pode-se dizer que o comerciante que foi alvo do presente estudo "evita a ostentação e as despesas desnecessárias, assim como o gozo consciente do seu poder, e embaraçam-no os sinais de reconhecimento social que recebe" e que, tal qual o protótipo do capitalista protestante weberiano, "[t]er um tipo de modéstia [...] não lhe é de modo algum, excepcional, mas muito mais a regra" (WEBER, 1987, p. 47). José Pinto nós dá um exemplo de como evitava despesas que podiam ser contornadas:

Eu sempre tinha que usar duas malas grandes. Nos ônibus as pessoas falavam: "uai, o senhor esta mudando muito hein!”. [...] Eu tinha uma atitude séria, porque aquele símbolo [da polícia do exército] que estava no meu braço [na manga da farda], eu tinha que respeitar ele, era polícia especial [o que dava direito a viajar de ônibus sem pagar a passagem]. Policial não era uma pessoal qualquer, é por isso. Então, eles tinham que aceitar aquilo. Mas eu não sentava. Ia no ônibus de pé. Dava oportunidade para o passageiro sentar. [...] Eu ia e voltava de pé. (Comunicação oral).

De toda maneira, se fosse necessária a classificação sumária dos mascates, caixeiros-viajantes e tropeiros numa das modalidades de gestão propostas por Weber (2004) - patrimonial e aquisitiva -, seria possível afirmar que praticavam a "[...] gestão aquisitiva econômica". Isso porque eles valiam-se do cálculo para

${ }^{7}$ Não se deve desconsiderar a possibilidade de as respostas terem evitado citar a acumulação e o lucro por ser essa uma característica da sociedade brasileira, como mostrou uma pesquisa de opinião realizada em 2005 e publicada pela Revista Exame (GUROVITZ e BLECHER, 2005). 
amealhar bens de maneira crescente e não apenas para manter sua subsistência com pouco excedente. ${ }^{8}$ É o que deixa entrever o comerciante José Pinto no relato abaixo:

Eu voltei por causa da mamãe. A nossa casa era uns esteios escorados no chão com pau pra não cair. Vinham aquelas chuvas, a mamãe pegava aquela água benta pra rezar, por causa daquela chuva. Pois eu vim pra cá e Deus ajudou que eu ganhei dinheiro e fiz uma casa pra nós morarmos, venci! Mas eu sou mascate até hoje. Eu comprava de tudo e vendia de tudo. Até hoje, todo mundo que chega aqui eu atendo ele. Se tiver dinheiro pra comprar dois quilos de fubá, eu vendo, mas tudo. (Comunicação oral).

Cabe salientar que os comerciantes entrevistados não eram ascetas protestantes do tipo ideal weberiano, mesmo porque essa é uma categoria analítica que não se encontra na realidade. No caso do presente estudo, algumas características que remetem a traços de cultura brasileira, como apontados por Sérgio Buarque de Holanda (1995), também podem ser identificados. A seguir, busca-se apresentar os principais pontos identificados que ilustram essa asserção.

\section{Traços de cultura brasileira}

Em contraponto às características colocadas por Weber (1987) e que podem ser consideradas como atributos dos comerciantes estudados, tem-se alguns apontamentos feitos por Sérgio Buarque de Holanda em sua obra seminal "Raízes do Brasil" ([1936] 1995). O autor aponta elementos que seriam constitutivos da cultura nacional e que teriam sido legados pelos portugueses: "Podemos dizer que de lá veio a forma atual de nossa cultura; o resto foi matéria que se sujeitou mal ou bem a essa forma" ([1936] 1995, p. 40). Passados já mais de setenta anos, nota-se a argúcia do autor que fez essas afirmações cerca de trinta anos antes de os sujeitos pesquisados exercerem suas atividades.

Coexistiriam então elementos que seriam marcadamente característicos do capitalista protestante e traços de personalismo e de irracionalidade herdados dos lusitanos. Assim,

[...] as qualidades morais que requer naturalmente a vida de negócios distinguem-se das virtudes ideais da classe nobre nisto que respondem, em primeiro lugar, à necessidade de crédito, não à de glória e de fama. São virtudes antes de tudo lucrativas, que à honra cavalheiresca e palaciana procuram sobrepor a simples honorabilidade profissional, e aos vínculos pessoais e diretos, a crescente racionalização da vida. (HOLANDA, 1995, p. 133).

Ou seja, se por um lado o apelo à afetividade persiste, por outro, ela não atende a todas as necessidades que a sociedade capitalista coloca. Assim, à simples fama ou honorabilidade, deve-se sobrepor a capacidade de obter crédito, que não necessariamente considera outros atributos a não ser a capacidade do tomador do empréstimo de saldar a dívida contraída.

Sucede, todavia, que

${ }^{8}$ Entretanto, principalmente entre os mascates e os tropeiros, no correr da viagem era comum que adquirissem bens para mera subsistência ou sem vinculação acumulativa imediata. 
[j]ustamente a repulsa firme de todas as modalidades de racionalização e, por conseguinte, de despersonalização, tem sido, até nossos dias, um dos traços mais constantes dos povos de estirpe ibérica [...] sabem muitos comerciantes de outros países que é da maior conveniência estabelecerem com eles vínculos mais imediatos do que as relações formais que constituem norma ordinária nos tratos e contratos. [...] [É] necessário, para conquistar um freguês no Brasil ou na Argentina, principiar por fazer dele um amigo. (HOLANDA, 1995, p. 133).

Os relatos coletados mostram que os sujeitos entrevistados têm em vista, por um lado, a necessidade de obter crédito para conseguir operar seu negócio e, por outro, o estabelecimento de relações afetivas, de cordialidade, e mesmo de amizade com aqueles com quem comercializavam. Isso sustenta a perspectiva de Holanda (1995), de que raramente se chegava a uma adequada racionalização nos negócios, tendo em vista a posição de amigo que o cliente geralmente assumia.

Weber (1987) aponta que a ação econômica capitalista repousa na expectativa de lucros valendo-se da prática de trocas, ou no que o autor chama de formas "pacíficas" de lucro. Ou seja, o cálculo racional deve estar presente, mas não o comportamento que aviltasse um ou outro partícipe da atividade de troca. A atividade "predatória", que não incluía a perspectiva de longo prazo, não se enquadraria no que Weber (1987) entende por ação capitalista racional, mas como tradicionalismo, que seria a atitude e a reação mais pungente para resistir de forma mais tenaz às novas demandas colocadas pelo espírito do capitalismo enquanto novo ethos social.

Holanda (1995, p. 135) parece concordar ao afirmar que "[a] simples ganância, o amor às riquezas acumuladas à custa de outrem, principalmente estranhos, pertence, em verdade, a todas as épocas e não caracteriza a mentalidade capitalista se desacompanhada de certas virtudes econômicas que tendam a contribuir decisivamente para a racionalização dos negócios”.

Tem-se, assim, um ponto importante referente aos relacionamentos estabelecidos entre comprador e vendedor no que concerne aos praticantes do comércio volante. Uma vez que eles se implicavam pessoalmente, as relações terminavam por não degringolar para um comportamento em que cada um buscasse adquirir vantagens que poderiam levar a outra parte a se sentir lesada. Em geral, o comércio se tornava uma busca para estabelecer relações que fossem satisfatórias para todos os partícipes da negociação, de modo a dar perenidade aos relacionamentos estabelecidos e que, diversas vezes, ultrapassavam a relação econômica pura.

Já na atualidade, o que se nota é uma substituição paulatina dos valores éticos tradicionais pelo cálculo racional-contábil na maior parte das relações. De fato, o desencantamento do mundo apontado por Weber (1987) não contribui para a manutenção dessas relações comerciais com resquícios de tradicionalismo. Estes ainda se verificam em alguns ambientes, principalmente nos pequenos negócios e nas empresas familiares, como nota também Sá (2010). Contudo, concorda-se com Vianna (1999, p. 46, grifo do autor), quando afirma, referindo-se especificamente ao Brasil pós-1988, que "[...] o moderno, pois, não veio a encantar $o$ mundo dos brasileiros, [...] mas a racionalizar a sua vida a partir de valores de mercado, como, aliás, seria de esperar de uma previsão weberiana".

Assim, em todas as esferas pode-se notar o avanço da razão instrumental sobre outras formas de direcionar o comportamento. As trocas comerciais tendem a se tornar cada vez mais controladas pelos sistemas de informação, que visam, também, diminuir a liberdade daqueles que estão envolvidos nas trocas. Some-se, ainda, o crescente aumento dos discursos que apelam para a profissionalização das empresas familiares com o intuito de escamotear da esfera dos negócios os comportamentos que não atendam à razão calculista. 


\section{As mudanças observadas na contemporaneidade}

O avanço do racionalismo nas relações entre os homens e a ascensão do pensamento instrumental calculista acabaram por diminuir o espaço para as relações pessoais no trato comercial que se observa na contemporaneidade. O que se vê é que

[...] a concepção de mundo teocêntrica e dualista é desvalorizada pela absolutização do ponto de partida do racionalismo da dominação do mundo motivado religiosamente, o que expressa o caráter autodestrutivo da ética protestante. O mesmo mundo que foi "encantado" através do simbolismo vem a ser, por força da necessidade do reconhecimento das leis específicas que o regem, desencantado. (SOUZA, 1998, p. 14).

Assim, a maior "eficiência", engendrada pela moral do protestante nas relações capitalistas que estabelecia, levara essa ética a assumir feições de comportamento hegemônico que acaba por ser imposto ao conjunto da sociedade devido à concorrência estabelecida no interior das sociedades capitalistas.

[...] Quando o ascetismo foi levado para fora dos mosteiros e transferido para a vida profissional passando a influenciar a moralidade secular, fê-lo contribuindo poderosamente para a formação da moderna ordem econômica e técnica ligada à produção em série através da máquina, que atualmente determina de maneira violenta o estilo de vida de todo indivíduo nascido sob esse sistema, e não apenas daqueles diretamente atingidos pela aquisição econômica, e, quem sabe, o determinará até que a última tonelada de combustível tiver sido gasta. (WEBER, 1987, p. 130-131).

Tonet (2002) aponta para o enfraquecimento dos padrões éticos que pode ser observado na realidade concreta. Tais padrões são substituídos por apelos moralizantes cada vez mais intensos; irrealizáveis, entretanto, sob a batuta da razão calculista. $\mathrm{O}$ autor questiona:

[...] O que se passa no terreno dos valores? Mesmo entre a maioria daqueles que se pretendem comprometidos com a construção de uma ordem social justa? Uma dissociação cada vez maior entre o discurso e a realidade objetiva. Enquanto esta última vai no sentido [...] de um aprofundamento na degradação da vida humana, o primeiro vai para o lado oposto: ou do apelo moralizante [...] ou das tentativas de fundar uma ética capaz de fazer frente a essa avalanche devastadora. (TONET, 2002, p. 6).

Desse modo, as relações estabelecidas hoje se situam num terreno de ambiguidade. Há divergência entre os padrões colocados pela ética aceita socialmente e as demandas do capitalismo contemporâneo. "Concretamente: uma é a lógica do ser, outra a lógica do dever ser. A um ser que vai no sentido de tratar tudo, inclusive os indivíduos, como coisas opõe-se o dever de tratar os indivíduos como fim" (TONET, 2002, p. 6).

Tem-se, então, movimentos distintos que podem ser percebidos pelos relatos dos sujeitos pesquisados, face ao cenário traçado até aqui: existe a valorização dos laços afetivos mesmo nas relações comerciais. Tal característica pode ser considerada parcialmente tributária da herança cultural e, ao mesmo tempo, um resquício tradicionalista no capitalismo desenvolvido no Brasil. Constata-se também um movimento generalizado de ampliação do domínio da racionalidade instrumental, a racionalidade técnica, valorizada pela lógica do 
[...] capitalismo tardio, ou seja, uma fase pós-liberal do capitalismo, em que a dominação social deixou de ser exclusivamente concebida como dominação de classe para tornar-se uma dominação da própria racionalidade incidente sobre a subjetividade dos indivíduos, configurando aquilo que ele [Adorno] chamava de uma sociedade administrada. (CAMARGO, 2006, p. 124-126, grifo nosso).

Em contraposição às raízes culturais brasileiras e às práticas efetivadas pelo comerciante-volante de meados do século XX, observa-se tendência a crescente racionalização no trato comercial e nas relações estabelecidas em geral. Além disso, a própria figura do representante comercial perde parte de sua relevância devido ao avanço observado nas tecnologias de informação. Na contramão desta tendência contemporânea, os comerciantes volantes faziam da pessoalidade presente nas relações uma forma de compreender a necessidade dos seus clientes - como se pode observar na fala do entrevistado José Pinto.

Tudo que me pedia eu anotava. Eu andava com um papelzinho no bolso. Tudo que pedia eu punha o nome e via. Guardava aquilo tudo pra da próxima vez eu chegar preparado. (Comunicação oral).

Além disso, por diversas vezes, os entrevistados deixavam entrever certo compromisso que ligava vendedor e comprador. A narrativa de Artêmio explicita essa ligação

Quando o concorrente chegasse [para vender vacinas contra aftosa], o cliente já estaria comprometido comigo. Comprou uma geladeira na minha mão, no [setor] comercial... Normalmente o pagamento era parcelado em doze meses. Aquela geladeira estaria destinada a receber vacina contra aftosa e não poderia guardar vacinas de outra marca, porque eu tinha conseguido o financiamento da geladeira para ele. Era um compromisso moral. (Comunicação oral).

A presença física de uma pessoa com um bloco para fazer pedidos deixa de ser um imperativo à efetivação de um negócio para se tornar, em parte, um capricho, uma espécie de tributo a um "tradicionalismo" da cultura brasileira, que não dispensou ainda as relações personalizadas. Para se escamotear o afeto, é mesmo desejável que se eliminem, ao máximo, as interações humanas durante as trocas.

\section{O Afeto ${ }^{9}$ na Relação Comercial}

À primeira vista, corre-se o risco de se pensar que todas as relações comerciais estão estabelecidas exclusivamente por critérios utilitários. Entretanto, como o próprio Weber (2004) permite entrever, a ação econômica não se pauta exclusivamente pelo racionalismo, pode também estar marcada por relações tradicionais ou afetivas. Assim, os achados dessa pesquisa coadunam-se com esse possível hibridismo para o qual o autor abre espaço.

\footnotetext{
${ }^{9}$ Concorda-se com Menezes (2007, p. 234) quando o autor afirma que "[...] as maneiras como o afeto (toda esta área semântica envolvendo a "afetividade") é referido e balizado nunca são unívocas". Entretanto, como não é proposta do texto discutir esse assunto em específico, observa-se que, aqui, afeto é entendido como um sentimento que se situa entre a simpatia e a amizade. Para uma discussão mais aprofundada sobre o termo, ver o próprio Menezes (2007).
} 
Guimarães (2008, p. 2), em seu estudo sobre relações entre comerciantes, consumidores e fornecedores, aponta que "[e]ssas relações são tipicamente urbanas e capitalistas e, consequentemente, pautadas, à primeira vista, na superficialidade e no anonimato. Entretanto, em dados contextos é mais fácil identificar outros valores que permeiam essas relações". Os achados da autora condizem com as conclusões às quais se chegou na pesquisa realizada com os praticantes do comércio volante. Além disso, percebe-se que há concordância neste ponto - em relação a outros elementos que não os econômicos nas práticas comerciais observadas com autores como Davel e Colbari (2000) e Garcia (2001). Entende-se que é possível aproximar em alguns pontos o modo como os comerciantes volantes agiam com as formas de organização e ação das empresas familiares e dos pequenos negócios em geral, mesmo os informais, em que se pode observar que diversas práticas são impregnadas pela afetividade (WAIANDT e DAVEL, 2008).

A importância dada ao relacionamento pessoal como motivação para compra foi aspecto recorrente na fala dos entrevistados - sobretudo no que diz respeito ao relacionamento que o cliente mantinha com aquele que representava diretamente a empresa, sendo este o mascate, o tropeiro ou o caixeiro. Era dada a possibilidade de se estabelecer um relacionamento entre sujeitos que se implicavam numa ação não apenas como profissionais, mas como pessoas dispostas a fundar a interação em outras bases que não o cálculo instrumental. Assim, um trecho da entrevista de Fernando mostra que as técnicas de venda são boas para lidar com empresas, mas, quando se trata de vender para pessoas, a situação muda um pouco:

Quando isso é para lidar com distribuidores, as regras de passo a passo ajudam muito. Agora quando é para lidar... que você tem que ir conversar direto com o produtor, já é diferente que você não visa lucro, você visa benefício.[...] Então, são duas particularidades diferentes que você tem que estar bem treinado [...] Muitas das vezes você tem que ser criativo. Às vezes você abandona tudo, às vezes é um bom dia, um relacionamento bem feito vai te ajudar muito mais a tirar um pedido do que uma técnica de venda. (Comunicação oral).

Acredita-se que o relacionamento dos comerciantes entrevistados se estabelecia até mesmo para abrandar a solidão, a saudade de casa e dos familiares e amigos. Admitia-se a questão do lucro e do ganho quase somente enquanto não suprimiam de todo a possibilidade do convívio mais familiar e de troca com o comprador. A expressão normal do respeito, em regra geral, parecia manifestar-se no desejo de estabelecer intimidade. Dois trechos de duas entrevistas diferentes, uma com Izabel e outra com Pintado, podem mostrar características do relacionamento pessoal íntimo que era estabelecido:

Olha, eu fui tão bem recebida onde eu fui, que grande fazendeiros de Anápolis, que ainda são meus amigos até hoje, de Uberaba, Uberlândia, Ituiutaba...O pessoal me tirava do hotel e me levava pra casa deles. Eu era convidada a ficar, não fiz a despesa de hotel, hospedar na casa deles e fazer meu trabalho sem ter despesa. Então eu fui muito feliz nessa historia (risos). Eu me dei muito bem (risos). (Comunicação oral).

Esse general, ele tinha que vir de Juiz de Fora aí. Ele ia ser homenageado lá na cidade de Nanuque, e o dono da casa de peças lá [cliente do mascate entrevistado], que é um grande amigo meu: "Oh Pintado, tem como você fazer um quibe pra ele ai? Fazer um quibe, a gente faz um quibe frito, quibe assado, quibe cru". Falei: "Faço! Você arranja duas cozinheiras pra me ajudar, só isso". Fiquei uma semana preparando o almoço pra esse General Quitiberê. Sabe esse bolinho de Badaró, que era tocador de violão e deputado. [...] Aí ele falou: "Quem é que fez esse quibe?". "Ah, foi aquele cara que tá ali" "Chama ele pra cá, uai. Senta aqui perto de mim". "No dia que você for a Juiz de Fora - ele era general lá em Juiz de Fora -, você vai na minha casa, fazer um quibe pra minha esposa". Falei: 


\begin{abstract}
"Perfeitamente, General, e se ficar ruim você não vai me mandar matar lá não, não é?" Então, é muito gostoso você... Eu fazia muito quibe no interior, pro pessoal comer. Os fregueses gostavam. (Comunicação oral).
\end{abstract}

Entretanto, permanece a sensação de que, com o constante avanço geral da razão subjetiva ou instrumental (HORKHEIMER, 2002; WEBER, 2004), as relações estabelecidas na prática do comércio tendem a se submeter cada vez mais ao cálculo, embora isto nunca se dê por completo. É claro, entretanto, que, em localidades específicas ou em pequenos comércios, é maior a resistência em se adotar novas práticas. Contudo haverá sempre a possibilidade de essas relações sucumbirem face ao avanço de empresas "mais modernas e racionais" - os supermercados em lugar dos armazéns de bairro, por exemplo.

Jorge e Bastos (2009, p. 30) apontam o desgaste dessa moral na sociedade contemporânea:

A lei que vale é a lei do capital, e a meta de vida é tornar-se rico, pois a riqueza é erigida como Bem Supremo. Surge um apelo ao gozo que autoriza um "vale-tudo", em cujo ringue tudo é possível, até mesmo transformar o homem em mero parafuso do maquinário produtor de gozo do capitalista, cujo óleo é o dinheiro. Dá-se, assim, a revogação da lei moral pela lei do capital.

Assim, com a instrumentalização das relações, a representação dos traços afetivos no dia a dia dos negócios é inadequada, arcaica e imprópria aos propósitos organizacionais, e embora se saiba que em algum nível sempre haverá o personalismo e a confiança de pessoa a pessoa, as empresas "modernas" buscam minimizar os efeitos dessas relações. Os espaços que admitem de bom grado essas manifestações de interpessoalidade são aqueles tidos como ainda não "profissionalizados" e nos quais o negócio não se dá apenas entre duas pessoas implicadas numa troca, mas entre sujeitos que se implicam diretamente na troca que efetuam, como aponta o entrevistado Ricardo:

[...] como representante... eu sou responsável pela venda, mesmo que você esteja só representando, há a que está vendendo e a que está comprando, mas eu sou responsável. [...] Não é aquele negócio, vendi e tal, pá, pá, acabou. Acabou minha responsabilidade, acaba ali [...] não vejo assim. [...] a venda só termina quando... vender, tem o pós-venda e tal, a satisfação do cliente, e a garantia que o cliente continue, né? Você fidelizar ele. (Comunicação Oral).

Nesses ambientes, as trocas comerciais podem ser ainda pautadas pela "confiança" em vez de se privilegiar um ambiente de negociação isento de valores que escapem ao cálculo contábil. Percebe-se que esses sujeitos podem privilegiar aspectos menos técnicos e, portanto, dão margem a relacionamentos menos padronizados.

Desse modo, observa-se que a proximidade pessoal, que não foi racionalmente planejada como um meio para se atingir outro objetivo, pode levar a falhas na programação das atitudes com relação aos clientes. Entretanto, isso reforça a ideia de que tal comportamento era parte da construção social do comerciante e do imbricamento do mundo da vida e do mundo dos negócios que observava.

Crê-se que os sujeitos pesquisados valiam-se do afeto nas suas relações comerciais não apenas porque desejavam ter um cliente a mais - apesar de este ser um fator que deve ser levado em consideração - mas porque viam sua vida e seu trabalho entremeados. Assim, não era possível seccionar o que faziam durante o exercício de sua atividade profissional dos julgamentos sobre si e sobre os outros em suas relações. Desta maneira, ficaria justificada uma relação entremeada por traços afetivos porque não seria "normal" conviver 
com alguém "apenas" por razões comerciais, mesmo que estas fossem preponderantemente lucrativas. Neste sentido, o entrevistado Naturib afirma com veemência:

[...] tenho muita saudade da minha freguesia, tenho. Tenho saudade da minha freguesia, que eu digo para todos... Nessas cidades pra fora tudo, todo mundo gosta de mim, graças a Deus. (Comunicação oral).

Parte dessas características pode ser encontrada ainda nas empresas familiares. Nestas, o que é muitas vezes chamado de paternalismo pode não ser mais do que a dificuldade em lidar com as pessoas apenas como instrumento. Trata-se, talvez, de uma resistência do comportamento tradicional dos sujeitos na sociedade brasileira às transformações advindas das novas configurações postas pelo capitalismo. Embora as empresas familiares não sejam objeto do presente estudo, acredita-se que nelas a afetividade e os comportamentos que não se pautam exclusivamente pelo cálculo contábil sejam observáveis com frequência. Waiandt e Davel (2008, p. 381) apontam que, em ambientes de empresas familiares, "[...] o relacionamento entre o proprietário e funcionários extrapola os limites de um contrato formal entre patrão e empregado, e permeia relações fortemente incrustadas por traços afetivos, exacerbando a dimensão emocional na organização".

Este paralelismo entre o caráter pessoal presente nas relações dos comerciantes e as empresas familiares se manifesta também na dificuldade em se estabelecer o que seria interesse da família e interesse da empresa (GERSICK et al., 2003). Desse modo, os laços afetivos se fazem sentir na empresa familiar, por exemplo, quando surge a necessidade de distribuir as atividades entre membros da família, sendo a inserção pautada mais na aproximação entre os pares que no caráter objetivo racional amplamente difundido na literatura de estratégia. Torna-se condição sine qua non o caráter afetivo entre os pares, uma vez que a própria relação de confiança e credibilidade é tida como pressuposto para as interações estabelecidas.

Não se deve, por certo, romancear o comportamento dos sujeitos entrevistados. Mas não se pode também ignorar que, em nenhuma das mais de trinta entrevistas realizadas, eram ignoradas as relações personalizadas entre comprador e vendedor. Por um lado, os praticantes do comércio-volante exerciam várias atividades que poderiam ser enquadradas nas diversas áreas funcionais da administração. Faziam isso tacitamente e como parte da totalidade de seu trabalho. Por outro, poderiam facilmente ter suas práticas classificadas como "irracionais" ou verem-nas desprezadas por não serem tidas como profissionalizadas. Isso acontece muitas vezes na empresa familiar quando se tenta levar a esta, como critério de "sucesso", o retorno financeiro proporcionado pelo negócio, ao passo que este sucesso poderia ser apenas a manutenção do negócio familiar e da família em si.

\section{Considerações Finais}

Almejou-se neste texto discorrer sobre a relação entre o trabalho exercido pelos mascates, caixeiros viajantes e tropeiros e suas condutas na vida em geral. Observou-se que, para estes, sujeitos não havia uma separação bem delimitada entre aquilo que faziam em suas atividades de trabalho e seus posicionamentos pessoais. No decorrer do texto, foram apresentadas algumas características dos tipos de capitalista de que trata Max Weber e se constatou que os praticantes do chamado comércio volante podem, em geral, ser considerados como um tipo híbrido, com traços tanto daqueles que o autor chamou de tradicionais quanto daqueles chamados por ele de modernos. 
Com base na obra de Sérgio Buarque de Holanda (1995), foram identificados alguns traços culturais apontados pelo autor que possivelmente contribuíram na construção do tipo híbrido de capitalista encontrado na pesquisa realizada. Além disso, notou-se que, na contemporaneidade, o avanço do que Weber chamava de "razão instrumental" tende a levar o comportamento do capitalista tradicional, que por vezes abre espaço para o afeto, a se limitar a espaços cada vez mais restritos. As empresas familiares, micro e pequenas empresas tendem a permanecer marcadas por elementos afetivos que a razão instrumental insiste em tratar como obsoletos e não profissionais.

Entende-se que em pesquisas futuras seria relevante deter-se por mais tempo na questão do afeto e de como ele interfere na gestão de organizações de diversos portes. Sabe-se que eliminá-lo por completo do cotidiano é algo impensável, mas entende-se que a sua substituição gradativa por comportamentos racionais e mediados pelo cálculo é também uma tendência. Poder-se-ia ainda avançar na análise da história dos sujeitos entrevistados, detendo-se por mais tempo no modo como geriam as empresas que muitas vezes estabeleciam, e nas práticas que utilizavam antes e depois de se fixarem em um local. Além disso, observar o lugar que ocupa o afeto, e como ele é tratado nas empresas familiares e nas teorias que versam sobre essas organizações, pode contribuir para se compreender de que maneira o capitalismo visa tornar instrumentais todas as relações.

Levando-se em conta a pouca atenção dada aos sujeitos anônimos nos estudos organizacionais, este texto terá cumprido boa parte de seu papel se chamar a atenção para os homens e mulheres que atuaram no Brasil por volta da metade do século XX. Saliente-se que estas pessoas têm mais de 65 anos e podem contribuir, ainda, para que se resgate parte da história da administração e dos administradores no país. A busca por uma teoria "genuinamente nacional" provavelmente não levaria a lugar algum. Na contemporaneidade observa-se que o capitalismo anglo-saxão, profundamente influenciado pela ética protestante, muito embora já adquirindo novas feições, tende a adquirir a hegemonia, seja nas relações efetivas, seja nas teorias que versam sobre elas. Note-se, contudo, que os sujeitos que atuaram no Brasil contribuíram com a construção do que podem ser consideradas especificidades na recepção desse capitalismo no país.

\section{Referências}

AGAR, M. The professional stranger. Orlando: Academic Press, 1980.

BARDIN, L. Análise de conteúdo. Lisboa: Edições 70, 2004.

CAMargo, S. Axel Honneth e o legado da teoria crítica. Política \& Trabalho: Revista de Ciências Sociais, n. 24, p. 123-138, abr. 2006.

DAVEL, E.; COLBARI, A. Organizações familiares: por uma introdução a sua tradição, contemporaneidade e multidisciplinaridade. Revista Organizações \& Sociedade, v. 7, n. 18, maio/ago., p. 45-64. 2000.

GARCIA, V. P. Desenvolvimento das empresas familiares. Rio de Janeiro: Qualitymark, 2001.

GERSICK, K. E. et al. De geração para geração: ciclos de vida das empresas familiares. São Paulo: Negócio Editora, 2003.

GOLDENBERG, M. A arte de pesquisar: como fazer pesquisa qualitativa em Ciências Sociais. Rio de Janeiro: Record, 1997.

GONZÁLEZ REY, F. Pesquisa qualitativa e subjetividade: os processos de construção da informação. São Paulo: Thompson Learning, 2005. 
GUIMARAES, A. C. R. O lugar do comércio: um estudo antropológico sobre a sociabilidade no bairro. Associação Brasileira de Antropologia, 2008. p. $1-19 . \quad$ Disponível em: <http://www.abant.org.br/conteudo/000NOTICIAS/Premios/LeviStrauss/ana.pdf>. Acesso em: 07 dez. 2009.

GUROVITZ, H.; BLECHER, N. O estigma do lucro. Exame.com, 2005 . Disponível em: <http://exame.abril.com.br/revista-exame/edicoes/0839/negocios/noticias/o-estigma-do-lucro-m0040657>. Acesso em: 10 jan. 2011.

HOLANDA, S. B. Raízes do Brasil. São Paulo: Cia das Letras, 1995.

HORKHEIMER, M. Eclipse da Razão. São Paulo: Centauro, 2002.

JORGE, M. A. C.; BASTOS, F. Trabalho e capitalismo: uma visão psicanalítica. Trivium, v. 1, n. 1, p. 21-33, 2009. Disponível em: <http://www.uva.br/trivium/edicao1/artigos-tematicos/2-trabalho-e-capitalismo.pdf>. Acesso em: 07 dez. 2009.

MARRE, J. L. História de vida e método biográfico. Cadernos de Sociologia, Porto Alegre, v. 3, n. 3, 1991.

MENEZES, A. P. Para pensar o afeto. Rev. Latinoam. Psicopat. Fund., v. X, n. 2, p. 213-254, jun. 2007. Disponível em: <http://www.fundamentalpsychopathology.org/art/jun2007/aluisio.pdf〉. Acesso em: 07 dez. 2009.

SÁ, M. G. de. Feirantes: Quem são? Como administram seus negócios? In: ENCONTRO ANUAL DA ANPAD, 34. , 2012, Rio de Janeiro. Anais... 2010, Rio de Janeiro. p. 1-17

SOUZA, J. A Ética protestante e a ideologia do atraso brasileiro. Rev. bras. Ci. Soc., São Paulo, v. 13, n. 38, out. 1998. Disponível em: <http://www.scielo.br/scielo.php?script=sci_arttext\&pid=S010269091998000300006\&lng=en\&nrm=iso>. Acesso em: 08 dez. 2009.

TONET, I. Ética e Capitalismo. Presença Ética, Recife, v. 02, p. 13-25, 2002.

TRIVIÑOS, A. N. S. Introdução à pesquisa em Ciências Sociais: a pesquisa qualitativa em educação. São Paulo: Atlas, 1987.

VIANNA, Luiz, W. Weber e a interpretação do Brasil. Novos Estudos CEBRAP, n. 53, p. 33-47, mar. 1999.

VILELA, S. L. de O. Racionalização e globalização: uma leitura a partir de Max Weber. Raízes, ano XVIII, n. 19, p. 37-48, mai. 1999.

WAIANDT, C.; DAVEL, E. Organizações, representações e sincretismo: a experiência de uma empresa familiar que enfrenta mudanças e sucessões de gestão. Revista de Administração Contemporânea, Curitiba, v. 12, n. 2, p. 369394, abr./jun., 2008.

WEBER, M. A ética protestante e o espírito do capitalismo. São Paulo: Pioneira, 1987.

Economia e sociedade: fundamentos da sociologia compreensiva. v. 1. Brasília: Editora Universidade de Brasília, 2004. 